\title{
A Fuzzy Levelised Energy Cost Method for Renewable Energy Technology Assessment
}

\author{
Daniel G. Wright ${ }^{1 *}$, Prasanta K. Dey ${ }^{1}$, John G. Brammer ${ }^{2}$ \\ ${ }^{1}$ Operations and Information Management Group, \\ Aston Business School \\ ${ }^{2}$ European Bioenergy Research Group \\ Aston University \\ Birmingham B4 7ET, United Kingdom \\ *Corresponding author: d.wright3@aston.ac.uk
}

\begin{abstract}
Renewable energy project development is highly complex and success is by no means guaranteed. Decisions are often made with approximate or uncertain information yet the current methods employed by decision-makers do not necessarily accommodate this. Levelised energy costs (LEC) are one such commonly applied measure utilised within the energy industry to assess the viability of potential projects and inform policy. The research proposes a method for achieving this by enhancing the traditional discounting LEC measure with fuzzy set theory. Furthermore, the research develops the fuzzy LEC (F-LEC) methodology to incorporate the cost of financing a project from debt and equity sources. Applied to an example bioenergy project, the research demonstrates the benefit of incorporating fuzziness for project viability, optimal capital structure and key variable sensitivity analysis decision-making. The proposed method contributes by incorporating uncertain and approximate information to the widely utilised LEC measure and by being applicable to a wide range of energy project viability decisions.
\end{abstract}

Keywords: uncertainty; project development; levelised energy cost (LEC) 


\section{Introduction}

Renewable energy technology (RET) deployment and investment continues to grow at an unprecedented rate with $44 \%$ of the total worldwide generation capacity added in 2011 coming from renewable sources (excl. large hydro) (UNEP, 2012). However, the deployment and viability of potential projects are highly subjective to policy and regulation (Hamilton, 2006), and meeting finance terms (1998). The UK Renewable Energy Roadmap (DECC, 2011) highlights these barriers and states the importance of creating the correct market conditions, such as 'ensuring long term investment certainty and 'encouraging innovation' by supporting emerging technologies. Core to this is the justification of 'value for money' or 'return on investment' if financed privately.

Asset finance either in the form of corporate, on-balance sheet financing or project financing is the largest source of capital for renewable energy deployment worldwide (UNEP, 2012). It is necessary to meet the finance terms of the lender or investor to secure debt and, in the case of project financing, equity. These terms are also highly sensitive to the same uncertainties with research showing that financing structure, technology type and market conditions are some factors that affect the required internal rate of return (IRR) threshold for the project to be viable, this can range from 7 to $30+\%$ (de Jager and Rathmann, 2008; Dunlop, 2006).

The levelised energy cost (LEC) is defined as "the discounted lifetime cost of ownership of using a generation asset converted into an equivalent unit cost of generation in $\mathfrak{f} / \mathrm{MWh}$ or $\mathrm{p} / \mathrm{kWh} "(2010)$. The Department of Energy and Climate Change (DECC), the International Energy Agency (IEA), and the National 
Renewable Energy Laboratory (NREL) frequently apply the LEC as a viability measure. In the UK, policy decisions are also often informed by levelised unit costs (Gross et al., 2007). The LEC measure has been utilised to assess wind generation potential in Nigeria (Adaramola et al., 2011), Turkey (Gökçek and Genç, 2009), and wave energy converter potential in Australia (Behrens et al., 2012). It has also been applied with multi-criteria decision-making techniques (Bhattacharyya, 2012), Monte-Carlo analysis for photovoltaic systems (Darling et al., 2011) and nuclear and fossil fuel power generation (Locatelli and Mancini, 2010). It is also utilised as an output indicator for optimal energy portfolio theory research (Locatelli and Mancini, 2011)

The levelised unit cost method cannot handle uncertainty or vagueness in the discount rate or in cash flow projections. Previous research has only limitedly mitigated this in the absence of data, by probabilistically deviating from a fixed mean value, typically with a 'normal' distribution (Ang et al., 1999; Locatelli and Mancini, 2010, 2011). Darling et al. (2011) also utilised Monte-Carlo simulation to probabilistically produce a distribution of LEC outputs in their Solar Advisor Model (SAM). Arguing that it was inadvisable to enter single or fixed inputs into a LEC forecast as this could give a 'misleading sense of certainty'. The probabilistic method is an improvement on the typical approach, but it is often unlikely that the decisionmaker has the necessary data to accurately or confidently map probability distribution functions (Kahraman et al., 2004). Furthermore, the existing deterministic or probabilistic use of the LEC method does not traditionally incorporate the cost of debt and equity financing the project. Earlier research by Wiser and Kahn (1996) and Wiser and Pickle (1997), later applied by de Jager and 
Rathmann (2008), do incorporate the cost of project finance deterministically to the LEC but this remains to be done with a probabilistic or alternative method.

Fuzzy set theory has been demonstrated as a useful method for renewable energy modelling and decision-making problems. Zangeneh et al. (2011) demonstrated a fuzzy multi-objective planning model for distributed RET generation with uncertainty. Their research shows that fuzzy set theory is also aptly suited to incorporating imprecision into the existing LEC calculation method. Fuzzy LEC (FLEC) provides an alternative to the probabilistic method for handling uncertainty. By accepting that in some cases such as project feasibility analysis where the decisionmaker is unable to fully utilise probability distributions as there is insufficient data to map 'normal' or other distribution types; fuzzy sets are better suited. Fuzzy cash flow analysis methods have been suggested in previous research (Boussabaine and Elhag, 1999; Kahraman et al., 2004; Kahraman et al., 2002), but not applied to the energy industry or incorporated into the LEC calculation. Renewable energy project development is the core focus of the research but the F-LEC method is applicable to all energy project types.

\section{Levelised Energy Cost}

As stated by Gross et al. (2007), there are two approaches to calculating the LEC: the discounting or annuity method. As the discount method is generally favoured (Allan et al., 2011; IEA/NEA, 2010), it is the applied method in this research. The discount method is the total present value of the costs divided by the total electrical output present value and is given by the IEA/NEA (2010) as: 
$L E C=P_{e}=\frac{\sum_{t}\left(\left(I_{t}+O \& M_{t}+F_{t}+C_{t}+D_{t}\right) *(1+r)^{-t}\right)}{\sum_{t}\left(E_{t} *(1+r)^{-t}\right)}$

Where:

$P_{e}$ is the price of electricity ( $£ /$ MWhe)

$I_{t}$ is the investment cost in year $\mathrm{t}$

$O \& M_{t}$ is the operations and management cost in year $\mathrm{t}$

$F_{t}$ is the fuel cost in year $\mathrm{t}$

$C_{t}$ is the carbon cost in year $\mathrm{t}$

$D_{t}$ is the decommission cost in year $\mathrm{t}$

$E_{t}$ is the electricity production in year $\mathrm{t}$

$(1+r)^{-t}$ is the discount factor for year $\mathrm{t}$

$r$ is the rate of discount $(\%)$

The discount rate for a project is fixed, although there has been arguments over the validity of this as some cost or revenue streams are more or less uncertain than others (Awerbuch, 2006 cited Heptonstall, 2007). Awerbuch, 2006 cited Heptonstall (2007) also cites Dennis Anderson who states that "the proper way to treat uncertainties in any component of costs, such as capital or fuel costs, is to address them explicitly by feeding their means, ranges and variations directly into the analysis". Fixed discount rates are commonly utilised in financial decision support systems within the energy discipline (Bakken et al., 2007; Messineo et al., 2012; van Dyken et al., 2010) despite these issues which may be due to the lack of forecasting information available. Previous research has also attempted to study the effect of a stochastic 
discount rate with a 'normal' distribution on the break-even price of a project (Ang et al., 1999). However, the discount rate remains static over the duration of the project lifecycle and utilises an estimated standard deviation.

\section{Method}

The proposed method applies fuzzy set theory concepts to the traditional approach of calculating the LEC to improve the measure's ability to accommodate uncertainty and vagueness. The second phase suggested integrates the financial terms into the new fuzzy LEC method to achieve a fuzzy levelised unit cost that includes the terms of debt and equity finance and the necessary returns to make a project viable.

\subsection{Fuzzy Sets}

Fuzzy set theory was first proposed in the 1960's by L.A. Zadeh and is conceptually easy to understand and apply. It is especially useful for “...decision-making in an environment of uncertainty and incompleteness of information" (Zadeh, 2002:ix). As the theory is different to the traditional probabilistic techniques, it does not require exact values to be attributed to functions or to be subsumed into a single deviation variable. Inputs can be approximate or 'fuzzy' which makes it ideal for future projections of cost and revenue of RETs.

Fuzzy sets are utilised within fuzzy set theory to represent a range of possible values or outcomes a set can take; put simply a fuzzy set is a function that captures uncertainty in a similar way to a probability distribution function within probability theory. A fuzzy set $\tilde{A}$ is a set of real numbers $\mathbb{R}$ characterised by means of a membership level $\mu_{\tilde{A}}(x), \mathbb{R} \rightarrow[0,1]$. Where the membership to set $\tilde{A}$ for each $x$ 
within the set $X$ is given as $\tilde{A}=\left\{\left(x, \mu_{\tilde{A}}(x)\right) \mid x \in X\right\}$. Expressed as a piecewise function $\tilde{A}=\langle a, b, c\rangle$ :

$\mu_{\tilde{A}}(x)=\left\{\begin{array}{l}0, \text { for } a \geq x \geq c \\ \frac{x-a}{b-a}, \text { for } a \leq x \leq b \\ \frac{c-x}{c-b}, \text { for } b \leq x \leq c\end{array}\right.$

Alternatively, the function can be represented graphically, as shown in Figure 1.

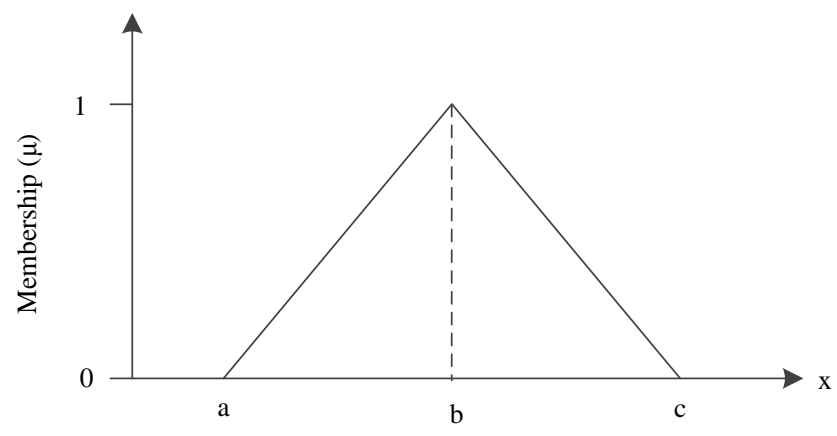

Fig. 1. Fuzzy set $\tilde{A}$

As stated in Dubois and Prade (1978) the greater the a and c the wider the spread and the fuzzier the number. Within the example set $\tilde{A}$ (Figure 1), the fuzzy triangular membership function is defined by its absolute minimum (a) and maximum (c) values which are the least expected to occur, and the most expected value (b).

A triangular distribution is given and utilised throughout the research to demonstrate the F-LEC approach, but it is possible to define and utilise a wide range of function types that include non-linear and non-symmetrical left and right hand bounds given that they remain:

- continuous non-increasing functions, defined on $[0,+\infty)$; 
- strictly decreasing to zero in those subintervals of the interval $[0,+\infty)$ in which they are positive, and fulfilling the condition $\mathrm{L}(0)=\mathrm{R}(0)=1$, and;

- the parameters a and $\mathrm{c}$ are non-negative real numbers.

(Chanas and Zieliński, 2001)

\section{2. $\alpha$-cuts}

The extension principle (Zadeh, 1965) is the underpinning theory for operations on fuzzy numbers. It 'extends' the operations and definitions of ordinary 'crisp' mathematical concepts to fuzzy sets. By taking $\alpha$-cuts of a fuzzy set, it is possible to produce non-fuzzy numbers that can undergo crisp mathematical arithmetic operations. $\alpha$-cuts are defined as a crisp set of elements belonging to a fuzzy set $\tilde{A}$ at least to the degree of $\alpha$ (Zimmerman, 1990):

$$
{ }^{\alpha} A=\left\{x \in X \mid \mu_{\tilde{A}}(x) \geq \alpha\right\}
$$

An example of an $\alpha$-cut, given in the context of the research, is each $\alpha \in(0,1]$ within the interval ${ }^{\alpha} A=\left[{ }^{\alpha} \underline{m},{ }^{\alpha} \bar{m}\right]=\left[\inf \left\{x \in X \mid \mu_{\tilde{A}}(x) \geq \alpha\right\}, \sup \left\{x \in X \mid \mu_{\tilde{A}}(x) \geq \alpha\right\}\right]$ (Chen, 2007). This is shown graphically in Figure 2.

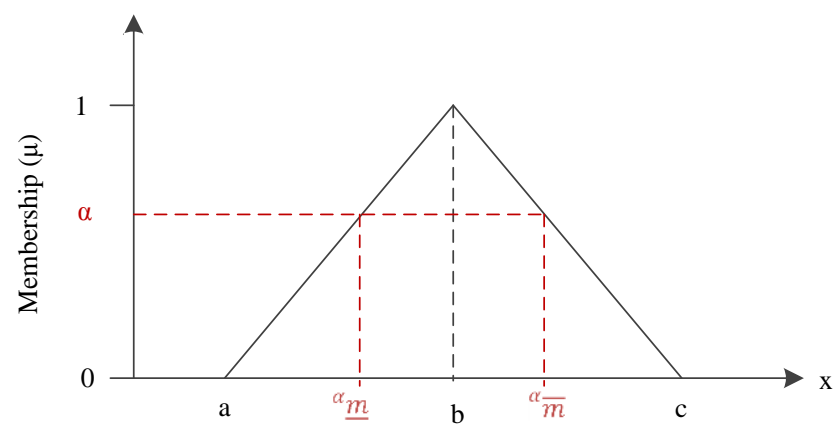

Fig. 2. Fuzzy set $\alpha$-cut 
Each cut of fuzzy set $\tilde{A}$ produces two crisp outputs $\left({ }^{\alpha} \underline{m},{ }^{\alpha} \bar{m}\right)$ that represent the lower and upper bounds of the function. These crisp $\alpha$-cuts can undergo the necessary mathematical arithmetic operations required to determine approximately the fuzzy output function. The number of $\alpha$-cuts can be arbitrarily selected depending on the level of precision required in mapping the output function.

\subsection{Project Finance}

There are two methods for asset financing projects: corporate and project financing. Corporate finance is on-balance sheet financing which de Jager and Rathmann (2008) states is the more utilised method of finance and can be more favourable as lending terms are based on the risk of the company rather than the individual project. Project financing is the alternative option for cases where there is insufficient capital within the organisation to fund the project with corporate financing or the project sponsor lacks the 'track record' to secure additional funding through the company. For project financing, capital is raised from a combination of debt, equity and credit sources and the loan structure relies on cash flows for payment and assets for security (Fight, 2005). Project financing can be beneficial for small to medium scale developers as there is limited or no financial recourse, meaning that multiple projects could be pursued without negative company-wide impacts (Wiser and Pickle, 1998). Project financing is the method applied in the research, although many parallels can be drawn with corporate financing.

There are several key financial covenants set by financiers for RET project finance. These covenants dictate the terms of finance required to make the project viable with 
sufficient safeguards to maximise the possibility that the original investment plus a return can be repaid.

\subsection{Debt Finance}

Debt is a loan typically provided by banks and repaid over the debt term in the form of a debt service payment. Debt is comprised of the principal and interest which is usually paid annually. The debt service annuity is calculated as:

$a_{t}=T_{d} / \frac{1-(1+r)^{-d_{T}}}{r}$

Where:

$a_{t}$ is the annuity in year $\mathrm{t}$

$T_{d}$ is the total debt

$r$ is the rate of discount $(\%)$

$d_{T}$ is the debt term

The debt provider also stipulates that there should be additional revenue over the debt term to protect the debt service payment if any unforeseen risks should occur or the project performs lower than expected. This is referred to as the debt service cover (DSC) and is calculated as a ratio (DSCR) of net operating income divided the debt service payment:

$D_{S C R}=\left(R_{t}-O \& M_{t}-F_{t}\right) / a_{t} \quad$ if $t \leq d_{T}$

Where: 
$R_{t}$ is the revenue in year $\mathrm{t}$

The DSCR can typically range from 1.3 to 2 depending on the risk or uncertainty for the RET (de Jager and Rathmann, 2008) and it is required to be maintained for the debt term.

\subsection{Equity Finance}

Equity is capital invested into the project by investors who are typically paid in return in dividends from the free cash flow (see table 6). Sometimes referred to as the equity IRR, as it includes the cost of servicing debt and tax, the IRR at this point is equal to the return on equity with the free cash flow being entirely paid to the equity investor and not retained by the project for other purposes. Moreover, this IRR is also the largest possible equity investor return from the future yearly project cash flows for the project to break-even, such that the project net present value for its lifecycle is equal to zero. When there are greater than two cash flow amounts there is not a method for directly calculating the IRR (Lasher, 2010), so it is necessary to rely on an iterative methods such as the Newton-Raphson and Secant methods. The Newton-Raphson method is the most widely utilised as it is employed in MS Excel to solve IRR equations. Named after Sir Isaac Newton and Joseph Raphson, the method was originally proposed as a better approximation method for finding the root of an equation. In the case of this research, it is the point at which the NPV is zero. As the research utilises MS Excel to determine the solution the iterative equation is not featured. There can be difficulties in calculating this method if there is non-convergence on the root, a poor estimate on the IRR or irregular cash flows to the project. 
To be financial viable, all types of private, public, community and not-for-profit projects expect that at least break-even will be achieved over the lifecycle of operation. However, the desired level of return depends on the developer type and their motivation. A private developer is likely to demand a higher IRR rate than that of community and not-for-profit developers. Furthermore, an equity investor's threshold or hurdle rate will depend on several project and external market factors. Dunlop (2006) deconstructed the likely IRR threshold for equity investors in operational or near operational wind projects into its components. This was later updated by de Jager and Rathmann (2008) and both are shown in Table 1.

Table 1. IRR components

\begin{tabular}{llll}
\hline Component & $\begin{array}{l}\text { Dunlop } \\
\text { (2006) }\end{array}$ & $\begin{array}{l}\text { de Jager and } \\
\text { Rathmann (2008) }\end{array}$ & Description \\
\hline Risk free rate & $3 \%$ & 3 to 5\% & Equivalent to 10 year Government bonds \\
\hline Risk premium & $4 \%$ & 4 to 5\% & $\begin{array}{l}\text { Similar asset classes to wind power: water } \\
\text { funds, comparable shipping deals etc. }\end{array}$ \\
\hline Equity fund fees & $2 \%, 3 \%$ & $2 \%, 3 \%$ & $\begin{array}{l}\text { Fund management fees and illiquidity } \\
\text { premium as the stock cannot be sold easily }\end{array}$ \\
\hline Technology premium & 3 to 5\% & 3 to 15\% & $\begin{array}{l}\text { Technology risk premium. Dunlop states } \\
\text { that established technologies, such as wind } \\
\text { power, may not receive the premium }\end{array}$ \\
\hline Regulatory premium & -3 to 3\% & -3 to 3\% & $\begin{array}{l}\text { Regulation risk relating to support schemes } \\
\text { and the energy market }\end{array}$ \\
\hline
\end{tabular}

The estimates in Dunlop's (2006) research are typically lower than that of de Jager and Rathmann (2008) possibly because his work was pre-global financial recession. Dunlop (2006) also mentions that it would be necessary in future for equity investors to accept the 'considerable' development risk of RETs, particularly in securing planning permission and grid connections. 


\subsection{Capital Structure}

Capital structure, often expressed as a ratio, is the mixture of debt and equity used to finance a project (Wiser and Pickle, 1998). The capital structure of a project has a direct effect on the levelised unit cost as debt tends to be less costly than equity and is therefore preferential. However, as it is a requirement that the project also meets the DSCR over the debt term, this also causes an increase in the LEC at higher levels of debt gearing. There is a point at which the ratio of debt to equity gives the lowest LEC and this has been demonstrated in previous work (de Jager and Rathmann, 2008; Wiser and Kahn, 1996; Wiser and Pickle, 1997).

\section{Fuzzy LEC Calculation}

If each variable in the discounting LEC (Eq. 1) is no longer crisp but a fuzzy set, the fuzzy LEC ( $\widetilde{\mathrm{LEC}})$ equation is:

$$
\widetilde{L E C}=\widetilde{P}_{e}=\frac{\sum_{t}\left(\left({\widetilde{I_{t}}}_{t}+{\widetilde{O \& M_{t}}}_{t}{\widetilde{F_{t}}}+{\widetilde{C_{t}}}+\widetilde{D_{t}}\right) *(1+\tilde{r})^{-t}\right)}{\sum_{t}\left(\widetilde{E_{t}} *(1+\tilde{r})^{-t}\right)}
$$

It is not possible for the $\widetilde{\mathrm{EC}}$ equation (Eq. 6) to be calculated directly. However, with the use of $\alpha$-cuts it is approximately calculated as:

$$
{ }^{\alpha} L E C=P_{e}=\frac{\sum_{t}\left(\left({ }^{\alpha} I_{t}+{ }^{\alpha} O \& M_{t}+{ }^{\alpha} F_{t}+{ }^{\alpha} C_{t}+{ }^{\alpha} D_{t}\right) *{ }^{\alpha}(1+r)^{-t}\right)}{\sum_{t}\left({ }^{\alpha} E_{t} *{ }^{\alpha}(1+r)^{-t}\right)}
$$

The minimum F-LEC to meet the finance terms including the minimum DSC and ROE is calculated with the following algorithm depicted in Figure 3. 


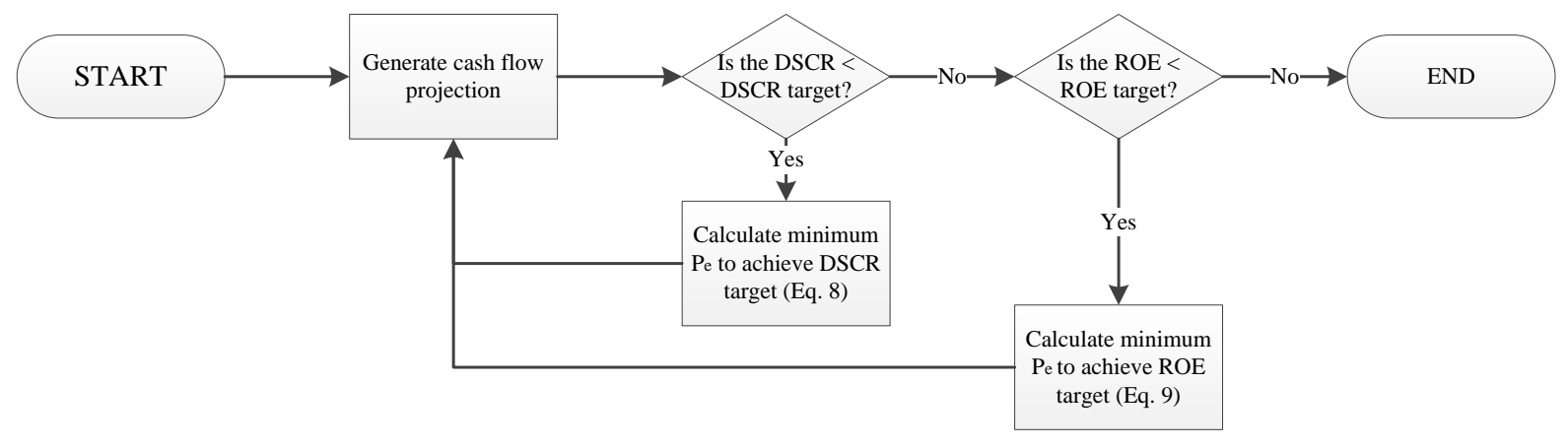

Fig. 3. F-LEC algorithm flow chart

The cash flow projection initialises with the $\alpha$-cuts of each of the fuzzy input variables (Eq. 6) and the price of electricity $P_{e}$ is set at $£ 0.01$. It is necessary to set $P_{e}$ at a value greater than zero so that it can be exponentially multiplied if Equation 9 is required. If a more simplistic linear and incremental $P_{e}$ is adopted then the starting value can be set to zero. The conditional DSCR and ROE loops are required within the algorithm to incorporate the finance terms and all possible configurations of debt and equity funding for the project.

If the DSCR for each year in the debt term is less than the target $D S C R_{t}^{T}$, the price of electricity is recalculated to meet the minimum threshold using the DSCR equation (Eq. 8):

$$
{ }^{\alpha} P_{e}=\left(\left(a_{t} \cdot D S C R_{t}^{T}\right)-\left({ }^{\alpha} O \& M_{t}+{ }^{\alpha} F_{t}-{ }^{\alpha} R_{t}\right)\right) / M W h e_{t}
$$

Where:

$P_{e}$ is the price of electricity ( $£ /$ MWhe)

$a_{t}$ is the annuity in year $\mathrm{t}$

$D S C R_{t}^{T}$ is the DSCR target in year t 
$O \& M_{t}$ is the operations and management cost in year $\mathrm{t}$

$F_{t}$ is the fuel cost in year $\mathrm{t}$

$R_{t}$ is the revenue in year $\mathrm{t}$

$M W h e_{t}$ is the MWe hours produced in year $\mathrm{t}$

The equation produces the minimum unit cost for electricity to achieve the debt financial covenants. The level of debt service cover must be at least at the level required by the lender, any less than this amount the lender will be unlikely to fund the project. Dependent on the level of gearing, the minimum price for electricity to meet the debt terms may be sufficient to also produce the required level of equity return. However, if the electricity price $P_{e}$ does not produce enough revenue to achieve the specified level of return the unit price has to be increased further through Equation 9:

${ }^{\alpha} P_{e+1}={ }^{\alpha} P_{e} \cdot \exp \left(R O E-R O E^{T}-0.0001 \%\right)^{\wedge}-0.05$

Where:

$R O E^{T}$ is the ROE target required for equity investment

The ROE calculation requires an incrementally increasing electricity unit price and then to be approximately determined with the Newton-Raphson method. If the $R O E$ is less than the target $R O E^{T}$, the price $P_{e+1}$ is multiplied by an exponential growth factor. This process is repeated until $R O E \geq R O E^{T}$. Equation 9 is designed to take exponentially reducing increments the closer the $R O E$ gets to the target. This saves 
computational processing time and can be replaced with a simple linear multiplier in place of the exponential multiplier applied in the algorithm.

\section{Example 1: Simple Fuzzy Conversion}

To demonstrate the application of the F-LEC without including the terms of finance, a notional case is given. Consider a $1 \mathrm{MWe}$ biomass electricity only power station with an operational life of 20 years with the crisp and fuzzy variables shown in Table 2.

Table 2. LEC inputs

\begin{tabular}{llllll}
\hline & & Crisp & Fuzzy & \\
\hline Variable & Unit & Value & $\boldsymbol{a}$ & $\boldsymbol{b}$ & $\boldsymbol{c}$ \\
\hline Discount rate & $\%$ & 15 & 12 & 15 & 17 \\
\hline Investment & $£, 000 \mathrm{~s}$ & 2000 & 1800 & 2000 & 2500 \\
\hline O\&M & $£, 000 \mathrm{~s} / \mathrm{yr}$ & 10 & 8 & 10 & 12 \\
\hline Fuel & $£, 000 \mathrm{~s} / \mathrm{yr}$ & 50 & 50 & 50 & 80 \\
\hline Carbon & $£, 000 \mathrm{~s} / \mathrm{yr}$ & 0 & 0 & 0 & 0 \\
\hline Decommission & $£, 000 \mathrm{~s}$ & 1500 & 1400 & 1500 & 1700 \\
\hline Electricity & MWhe/yr & 7800 & 7000 & 7800 & 8000 \\
\hline
\end{tabular}

For simplicity, the project investment costs are incurred in year 0 and the plant is operational for the entire year. The total investment cost is $£ 2$ million and the operations and management $(\mathrm{O} \& \mathrm{M})$ costs are estimated at $£ 10 \mathrm{k}$ a year with the possibility of being $\pm £ 2 \mathrm{k}$ around that estimate. The plant burns biomass wood chip that costs c.£50k pa but could potentially, due to market uncertainty, rise to c.£80k pa. There are no carbon costs for the project as the feedstock is entirely derived from biomass sources making the project exempt for the Emissions Trading System (EU ETS). The plant is estimated to operate at $90 \%$ availability which results in 7800MWhe/pa, although this could in the worst case scenario fall to $7000 \mathrm{MWhe} / \mathrm{pa}$ or in the best case be $8000 \mathrm{MWhe} / \mathrm{pa}$. As in Ang et al. (1999), a range of possible 
discount rates are applied over the operational lifecycle but with a fuzzy distribution as an alternative to the probabilistic one applied in their research. Finally, as used as the upper cost estimate in IEA/NEA (2010), the decommission costs of the plant are estimated to be $10 \%$ of the investment cost and are distributed over the last 10 years of the plants operational life.

Table 3. Discounted cash flow for crisp and fuzzy at $\alpha$-cut $=1$

\begin{tabular}{|c|c|c|c|c|c|c|c|c|}
\hline \multicolumn{9}{|c|}{ Year } \\
\hline Variable & Unit & $\mathbf{0}$ & 1 & 2 & $\ldots$ & 17 & 18 & 19 \\
\hline Costs & & & & & $\ldots$ & & & \\
\hline Investment & $£, 000 \mathrm{~s}$ & 2000 & 0 & $\overline{0}$ & $\ldots$ & 0 & 0 & 0 \\
\hline $\mathrm{O} \& \mathrm{M}$ & $£, 000$ s & 10 & 8.7 & 7.56 & $\ldots$ & 0.93 & 0.81 & 0.7 \\
\hline Fuel & $£, 000 \mathrm{~s}$ & 50 & 43.48 & 37.81 & $\ldots$ & 4.65 & 4.04 & 3.51 \\
\hline Carbon & $£, 000 \mathrm{~s}$ & 0 & 0 & 0 & $\ldots$ & 0 & 0 & 0 \\
\hline Decommission & $£, 000 \mathrm{~s}$ & 0 & 0 & 0 & $\ldots$ & 1.86 & 1.62 & 1.41 \\
\hline Production & & & & & $\ldots$ & & & \\
\hline Electricity & MWhe & 7800 & 6782.61 & 5897.92 & $\ldots$ & 724.82 & 630.28 & 548.07 \\
\hline Unit Cost & & & & & $\ldots$ & & & \\
\hline Annual unit cost & £/MWhe & 264.1 & 7.69 & 7.69 & $\ldots$ & 10.26 & 10.26 & 10.26 \\
\hline LEC & £/MWhe & 43.82 & & & & & & \\
\hline
\end{tabular}

By applying Equation 1, the notional project has a crisp discounted LEC of $£ 43.82$.

Whereas, the F-LEC (Eq. 3) produces a fuzzy function of possible LECs at the $12 \alpha$ cuts across the membership possibility scale (Table 4).

Table 4. Example 1 F-LEC $\alpha$-cuts

\begin{tabular}{lll}
\hline & \multicolumn{2}{l}{ LEC (£/MWhe) } \\
\hline $\boldsymbol{\alpha}$-cut & LB & UB \\
\hline 1 & 43.822 & 43.822 \\
\hline 0.9 & 42.842 & 45.94 \\
\hline 0.8 & 41.877 & 48.119 \\
\hline 0.7 & 40.928 & 50.361 \\
\hline 0.6 & 39.993 & 52.668 \\
\hline 0.5 & 39.073 & 55.042 \\
\hline 0.4 & 38.167 & 57.486 \\
\hline 0.3 & 37.277 & 60.001 \\
\hline 0.2 & 36.401 & 62.589 \\
\hline 0.1 & 35.54 & 65.254 \\
\hline 0.01 & 34.777 & 67.72 \\
\hline 0.001 & 34.702 & 67.97 \\
\hline
\end{tabular}


Shown graphically (Figure. 4), the F-LEC function ranges from approximately $£ 34.70$ to $£ 67.97$ per MWhe, with the expected value being $£ 43.82$. It is necessary for the project to be viable under all possibilities to obtain at least $£ 67.97$ per MWhe when selling the electricity onsite or by exporting it to a licensed electricity supplier and through revenue generated from production incentives such as a feed in tariff.

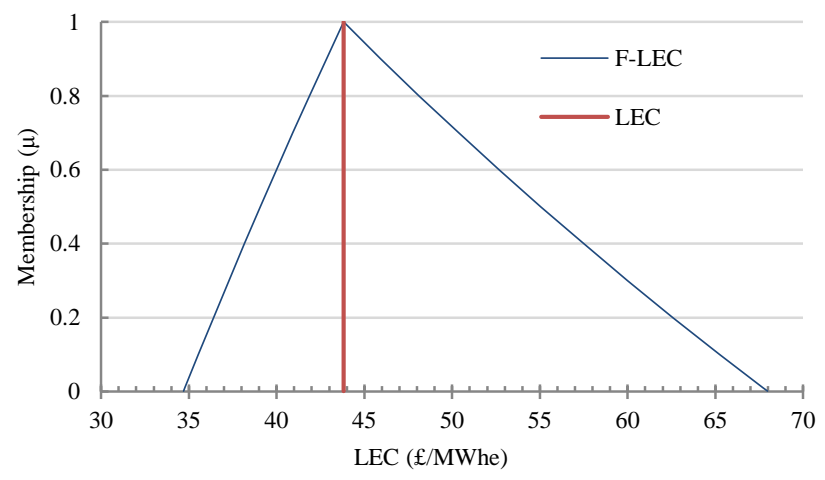

Fig. 4. Traditional LEC and F-LEC comparison

The F-LEC method is an improvement on the traditional LEC as it encompasses uncertainty in the variables, thus giving a truer reflection of the possible range of unit costs. However, the method does not account for the financial terms that often dictate project financing cash flow.

\section{Example 2: Finance Terms Included}

This section more fully applies the F-LEC principle to a case by including the financial covenants required to finance a RET and by utilising the algorithm in Section 4. The fuzzy distributions are the same as in Example 1, with the additional requirement that the following terms in Table 5 are met.

Table 5. Finance terms

Variable Value




\begin{tabular}{ll}
\hline Debt Term (Yrs) & 10 \\
\hline Debt Interest (\%) & 6 \\
\hline Debt Service Cover Ratio & 1.35 \\
\hline Return on Equity (\%) & 15 \\
\hline Tax $(\%)$ & 26 \\
\hline
\end{tabular}

It is possible for the project to receive debt financing at $6 \%$ interest with a 10 -year debt term. During this period, the debt provider requires that there is a minimum DSCR of 1.35 . The terms of equity are a $15 \%$ return over the project's 20 -year operational lifecycle. To calculate the IRR, the initial investment of the project occurs in year 0 and the project is not fully operational until the first year. Furthermore, tax on any profit is set at $26 \%$.

For the cash flow projection, 10-year straight-line depreciation on the investment is assumed. Renewable electricity production incentives have been removed for ease as multiple options exist and so that the price is somewhat comparable to the previous example. In the first section of the results (6.1), it is assumed that the project has a $60 \%$ debt gearing with the remaining capital being met by equity sources. Whereas, in the fuzzy project gearing results (6.1.1) it is assumed that the developers of the project are interested in calculating the minimum F-LEC under a range of debt to equity configurations available when attempting to secure finance. Finally, a F-LEC sensitivity analysis is demonstrated in Section 6.1.2.

\subsection{Results}

Table 6 shows the project cash flow projection at a $60 \%$ gearing of debt to equity at the $\alpha$-cut of 1 .

Table 6. Expected cash flow at $\alpha$-cut $=1$ 


\begin{tabular}{|c|c|c|c|c|c|c|c|c|}
\hline & & Year & & & & & & \\
\hline Variable & Unit & 1 & 2 & 3 & $\begin{array}{ll}\ldots 10 \\
\end{array}$ & $\ldots$ & 19 & 20 \\
\hline Depreciation & & & & & ... & $\ldots$ & & \\
\hline Beginning of year & $£, 000 \mathrm{~s}$ & 2,000 & 1,800 & 1,600 & $\ldots 200$ & $\ldots$ & - & - \\
\hline Depreciated & $£, 000 \mathrm{~s}$ & 200 & 200 & 200 & ...200 & $\ldots$ & - & - \\
\hline End of year & $£, 000 \mathrm{~s}$ & 1,800 & 1,600 & 1,400 & $\ldots 0$ & $\ldots$ & - & - \\
\hline Debt & & & & & .. & $\ldots$ & & \\
\hline Begin Yr debt & $£, 000 \mathrm{~s}$ & 1,200 & $1,108.958$ & $1,012.454$ & $\ldots 153.813$ & $\ldots$ & - & - \\
\hline Debt amortisation & $£, 000 \mathrm{~s}$ & 163.042 & 163.042 & 163.042 & $\ldots 163.042$ & $\ldots$ & - & - \\
\hline Interest & $£, 000 \mathrm{~s}$ & 72 & 66.538 & 60.747 & .. 9.229 & $\ldots$ & - & - \\
\hline Principal & $£, 000 \mathrm{~s}$ & 91.042 & 96.504 & 102.294 & $\ldots 153.813$ & $\ldots$ & - & - \\
\hline End Yr debt amount & $£, 000 \mathrm{~s}$ & $1,108.958$ & $1,012.454$ & 910.160 & $\ldots 0$ & $\ldots$ & - & - \\
\hline Production & & & & &.. & $\ldots$ & & \\
\hline Electricity production & MWhe & 7,800 & 7,800 & 7,800 & $\ldots 7,800$ & $\ldots$ & 7,800 & 7,800 \\
\hline Income & & & & & .. & $\ldots$ & & \\
\hline Energy revenue & $£, 000 \mathrm{~s}$ & 399.053 & 399.053 & 399.053 & $\ldots 399.053$ & $\ldots$ & 399.053 & 399.053 \\
\hline Costs & & & & & ... & $\ldots$ & & \\
\hline Fuel & $£, 000 \mathrm{~s}$ & -50 & -50 & -50 & $\ldots-50$ & $\ldots$ & -50 & -50 \\
\hline $\mathrm{O} \& \mathrm{M}$ & $£, 000 \mathrm{~s}$ & -10 & -10 & -10 & $\ldots-10$ & $\ldots$ & -10 & -10 \\
\hline Decommission & $£, 000 \mathrm{~s}$ & - & - & - & $\ldots-$ & $\ldots$ & -20 & -20 \\
\hline EBITDA & $£, 000 s$ & 282.710 & 282.710 & 282.710 & 282.710 & 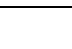 & 262.710 & 262.710 \\
\hline Depreciation & $£, 000 \mathrm{~s}$ & -200 & -200 & -200 & $\ldots-200$ & $\ldots$ & - & - \\
\hline EBIT & $£, 000 \mathrm{~s}$ & 82.710 & 82.710 & 82.710 & .. 82.710 & $\ldots$ & 262.710 & 262.710 \\
\hline Interest & $£, 000 \mathrm{~s}$ & -72 & -66.538 & -60.747 & $\ldots-9.229$ & $\ldots$ & - & - \\
\hline EBT & $£, 000 \mathrm{~s}$ & 10.710 & 16.172 & 21.963 & .. 73.481 & $\ldots$ & 262.710 & 262.710 \\
\hline Income tax & $£, 000 \mathrm{~s}$ & 2.785 & 4.205 & 5.710 & .. 19.105 & $\ldots$ & 68.305 & 68.305 \\
\hline After tax & $£, 000 \mathrm{~s}$ & 7.926 & 11.968 & 16.253 & .. 54.376 & $\ldots$ & 194.405 & 194.405 \\
\hline Return depreciation & $£, 000 \mathrm{~s}$ & 200 & 200 & 200 & ...200 & $\ldots$ & - & - \\
\hline Deduct principal & $£, 000 \mathrm{~s}$ & -91.042 & -96.504 & -102.294 & $\ldots-153.813$ & $\ldots$ & - & - \\
\hline Free cash flow & $£, 000 \mathrm{~s}$ & 116.884 & 115.464 & 113.958 & $\ldots 100.563$ & $\ldots$ & 194.405 & 194.405 \\
\hline$R O E$ & $\%$ & 15.00 & & & .. & $\ldots$ & & \\
\hline Coverage Ratios & & & & & .. & $\ldots$ & & \\
\hline Debt Service Cover & $£, 000 \mathrm{~s}$ & 282.710 & 282.710 & 282.710 & ... 282.710 & $\ldots$ & - & - \\
\hline DSCR, MAX: & & 1.734 & 1.734 & 1.734 & $\ldots 1.734$ & $\ldots$ & - & - \\
\hline$L E C$ & f/MWhe & 43.94 & & & ... & $\ldots$ & & \\
\hline
\end{tabular}

Similarly to Example 1, Table 6 portrays a project future projection of costs and revenues. However, this table also accounts for the depreciation of assets, interest on debt, tax on earnings and the required equity dividends. The values within the table are not present values as the discounting occurs when calculating the ROE from the free cash flow. Furthermore, to satisfy the algorithm in Section 4 the DSCR is in excess of the required minimum and therefore the LEC required to break-even is dictated by achieving the return on equity. 
The fuzzy LEC required for meeting the finance terms where there is vagueness in the future costs and energy production of the plant are shown graphically in Figure 5.

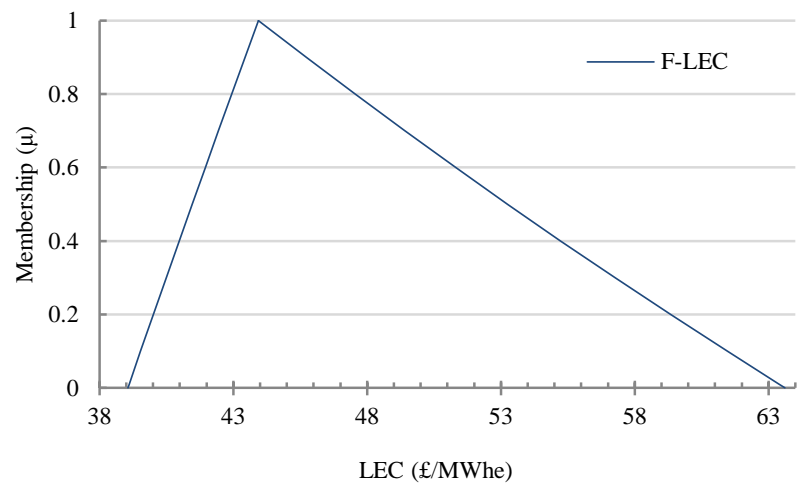

Fig. 5. Example 2 F-LEC

The F-LEC output form is similar to Figure 4 from Example 1, but the absolute minimum and maximum range is reduced as the IRR is given as a fixed discount rate as opposed to the fuzzy rate used previously. If the project is completely equity funded in an effort to more closely resemble Example 1, then the minimum LEC required to break-even is significantly higher. This is caused by incorporating the additional financial factors, such as the project finance terms and tax into the final LEC. An increase in the LEC also highlights the importance of taking viability and policy decisions with the inclusion of the costs necessary to commercially develop projects whereas their exclusion may be misleading to decision-makers.

\subsubsection{Fuzzy Capital Structure}

The capital structure of a project is commonly comprised of debt and equity, with a gearing ratio for the proportion of these two finance sources. It is possible when the terms of finance for these two capital sources are known or estimated to not only 
approximately calculate the F-LEC for a fixed configuration but also over the available spectrum of gearing ratios. This application has been demonstrated in earlier work (de Jager and Rathmann, 2008; Wiser and Kahn, 1996; Wiser and Pickle, 1997) but without the application of uncertainty or vagueness in the project variables. Although it is likely to be stipulated by the debt provider that there is a minimum level of equity from the sponsor, it may be beneficial to exceed this and increase the equity share to ultimately lower the unit costs.

Table 7. Project Gearing F-LEC $\alpha$-cuts

\begin{tabular}{llll}
\hline \multicolumn{4}{l}{ LEC (£/MWhe) } \\
\hline Debt & Abs. Min & Expected & Abs. Max \\
\hline $\mathbf{6 0 \%}$ & $\mathbf{3 9 . 0 6 0}$ & $\mathbf{4 3 . 9 3 7}$ & $\mathbf{6 3 . 6 0 5}$ \\
\hline $62 \%$ & 38.697 & 43.524 & 63.029 \\
\hline $64 \%$ & 38.337 & 43.114 & 62.458 \\
\hline $66 \%$ & 38.004 & 42.734 & 61.930 \\
\hline $68 \%$ & 37.693 & 42.380 & 61.436 \\
\hline $70 \%$ & 37.393 & 42.039 & 60.961 \\
\hline $\mathbf{7 2 \%}$ & $\mathbf{3 7 . 1 0 1}$ & $\mathbf{4 1 . 7 0 6}$ & $\mathbf{6 0 . 4 9 8}$ \\
\hline $74 \%$ & 37.794 & 42.495 & 61.597 \\
\hline $76 \%$ & 38.620 & 43.436 & 62.907 \\
\hline $78 \%$ & 39.445 & 44.377 & 64.217 \\
\hline $80 \%$ & 40.271 & 45.317 & 65.527 \\
\hline
\end{tabular}

Table 7 features the extremities of the F-LEC function at 10 debt gearing points of $2 \%$ intervals. The absolute minimum (abs. min) and maximum (abs. max) columns are the lower and upper bound ${ }^{0.001}$ LEC respectively. The expected column is the union of the lower and upper bounds at ${ }^{1}$ LEC. At a gearing of $60 \%$ debt the expected LEC is the same as shown in Table 6. The table also highlights that the optimal gearing of debt to equity for this project is c.72\%, where the lowest LEC are for each point on the function. The F-LEC range of debt to equity gearing is also shown graphically in Figure 6. 


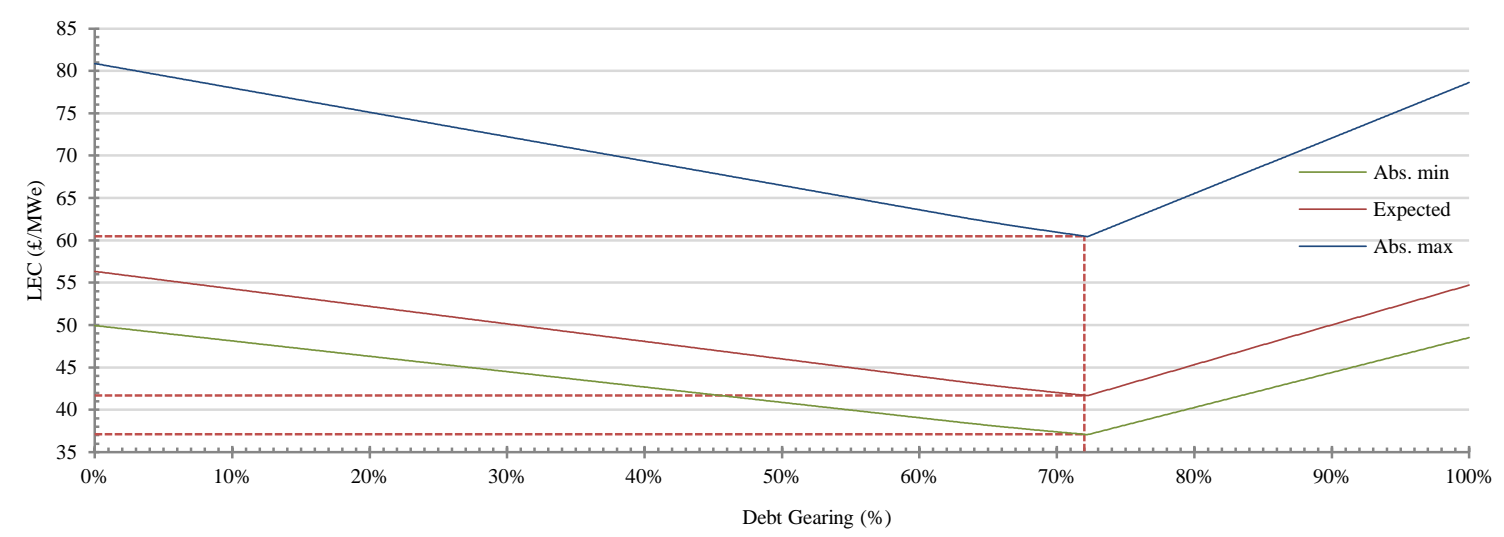

Fig. 6. Fuzzy capital structure

An alternative view is given within the figure of the absolute min, expected and absolute max LEC value at each gearing point. A cross section at a gearing of $60 \%$ would reproduce Figure 5. Ideally, a decision-maker would try to achieve a gearing at or close to the lowest possible range of fuzzy unit costs. This technique with the inclusion of uncertainty can support developers when negotiating the project terms of finance and capital structure or to assess the viability of possible financing options.

\subsubsection{Fuzzy Sensitivity Analysis}

The F-LEC method can also help to improve a traditional sensitivity analysis by incorporating uncertainty, as shown with the example given in Figure 7. The addition of the absolute min and max bounds within the sensitivity analysis incorporates the uncertainty or approximate mapping of other variables within the fuzzy cash flow analysis. Increasing information certainty by the decision-maker would reduce the fuzzy range given and in turn increase confidence in achieving the expected LEC value. 


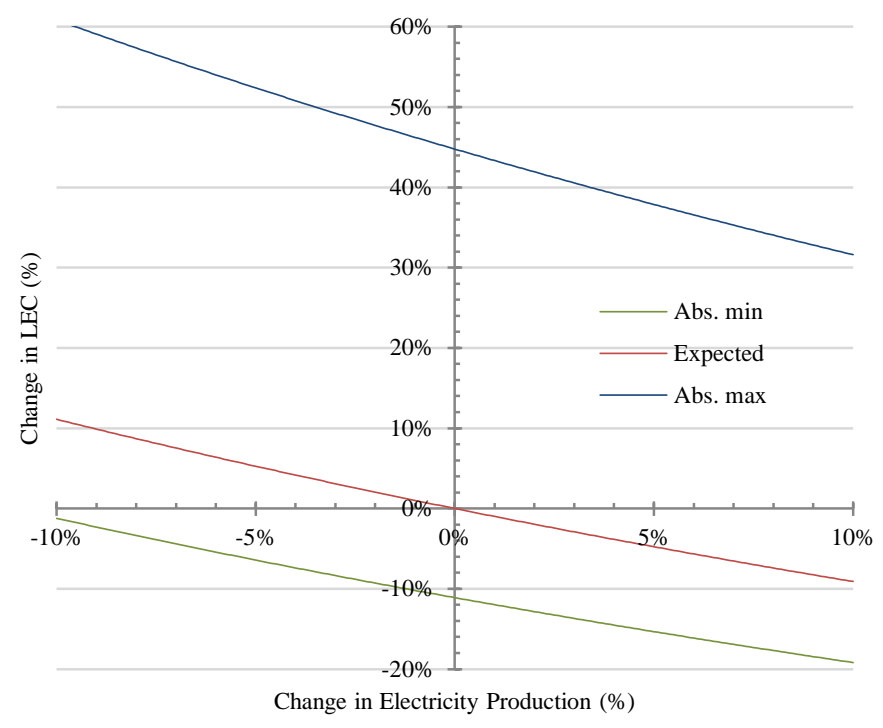

Fig. 7. Fuzzy sensitivity analysis for electricity production

Figure 7 illustrates the effect of a change in electricity production over the project's operational lifecycle on the base case LEC at a project gearing of $60 \%$. As expected, the figure shows that an increase in electricity production reduces the unit costs and a reduction in electricity production increases the unit costs. It is possible to apply this method to any of the project variables in a similar way to a traditional sensitivity analysis.

\section{Preliminary Findings}

As part of a larger research project, the F-LEC method was demonstrated to and utilised by five active practitioners in the UK renewable energy industry. They scored on a five point Likert-scale the usefulness of: (a) handling uncertainty when calculating a project's levelised energy cost, and; (b) to what level it is captured in the proposed F-LEC method. The results of this are given in Table 8.

Table 8. Participant scoring

\begin{tabular}{lll}
\hline Participant & (a) & (b) \\
\hline 1 & Extremely (5) & Very high (5) \\
\hline
\end{tabular}




\begin{tabular}{lll}
\hline 2 & Extremely (5) & Very high (5) \\
\hline 3 & Very (4) & High (4) \\
\hline 4 & Very (4) & High (4) \\
\hline 5 & Very (4) & Very high (5) \\
\hline
\end{tabular}

Both surveyed questions scored very well with a clear benefit to adding an 'uncertainty' element of functionality and its translation into the suggested F-LEC method. These preliminary findings indicate that explicitly being presented with the ranges of possibilities given approximate information or uncertainty is beneficial to decision-makers within the industry. However, a more comprehensive study is required to empirically confirm this finding.

\section{Conclusion}

The research demonstrated how the traditional crisp LEC method is insufficient in accommodating uncertainty or imprecision and that a solution to this shortcoming is to apply the proposed F-LEC method. It also demonstrates how the F-LEC method can include the terms of finance to give a unit cost that reflects the cost of financing a project. The proposed method for enhancing the traditional discounting LEC calculation can be easily applied to project cash flow projections to ascertain viability and when informing technology and policy decisions. By integrating the terms of project finance into the F-LEC, it is also useful to project sponsors and financiers as an alternative or additional measure to the IRR in cases of uncertainty and vagueness. A 20 year operational lifecycle is shown for both examples but this may differ depending on the energy project type. A change in the operational lifecycle will affect the levelised energy costs as there is a greater or shorter period to generate revenue and break-even. There may also be changes to the terms of finance 
with an example being the duration of dividend pay-outs and return to the equity investor.

The fuzzy method is an alternative to probabilistically calculating the LEC and potentially better suited when there is limited or approximate information held by decision-makers. Furthermore, the method, without incorporating the finance terms, does not employ an iterative process as required for the stochastic Monte-Carlo method. A non-iterative process such as the proposed fuzzy method is computationally quicker than a Monte-Carlo approach, for example the Darling et al. (2011) study utilised 1 million iterations of the calculation to produce each final solution. Additionally, the fuzzy set outputs explicitly display the consequences of uncertainty in the inputs, whereas probabilistic outputs may incorporate this into a single confidence level output variable.

An example of the application to a bioenergy project is given within the research but the method can be applied to a wide range of energy projects with or without the integration of the terms and cost of financing. The method can enhance the level of information presented to decision-makers by including uncertainty and this is demonstrated with the capital structure and sensitivity analysis outputs as well as with the LEC calculation. The surveyed practitioners clearly felt that this is beneficial to them in the early stages of project development. It is also possible with this type of method to track reductions in uncertainty held by decision-makers as they progress through the development of the project and a function's 'fuzziness' may reduce over time. 
The demonstrated method gives an alternative approach to modelling discount rates when there is limited information available to decision-makers. The concerns of Awerbuch, 2006 cited Heptonstall (2007) are also less contentious when uncertainty and variance in forecasting the discount rate and other variables are incorporated into the F-LEC calculation. Fuzzy discount rate mapping with the $\alpha$-cuts method replicates the many possible outcomes of variable discount rates within the fuzzy set output over the project duration. This is not an exclusive capability of the fuzzy approach but it is beneficial to the typical deterministic approach. Similarly to Ang, Huang [16], the applied method also demonstrates that the minimum LEC and in turn break-even point is highly dependent on the discount rate applied and project capital structure. Further developments of the F-LEC calculation could introduce more complex fuzzy set function mapping such as asymmetrical distributions known as LR type functions as first proposed by Dubois and Prade (1978). The impact of more complex and potentially non-linear fuzzy input functions in place of the triangular one demonstrated within the research on the output variable depends on the significance of the input function in the F-LEC calculation.

\section{Acknowledgements}

This work was supported by the Economic and Social Research Council [ES/H035818/1] and through the EREBUS (Engaging Research for Business Transformation) cluster in the West Midlands region of the UK.

\section{References:}

Adaramola, M.S., Paul, S.S., Oyedepo, S.O., 2011. Assessment of electricity generation and energy cost of wind energy conversion systems in north-central Nigeria. Energy Conversion and Management 52, 3363-3368. 
Allan, G., Gilmartin, M., McGregor, P., Swales, K., 2011. Levelised costs of Wave and Tidal energy in the UK: Cost competitiveness and the importance of "banded" Renewables Obligation Certificates. Energy Policy 39, 23-39.

Ang, B.W., Huang, J.P., Poh, K.L., 1999. Break-even price of distributed generation under uncertainty. Energy 24, 579-589.

Bakken, B.H., Skjelbred, H.I., Wolfgang, O., 2007. eTransport: Investment planning in energy supply systems with multiple energy carriers. Energy 32, 1676-1689.

Behrens, S., Hayward, J., Hemer, M., Osman, P., 2012. Assessing the wave energy converter potential for Australian coastal regions. Renewable Energy 43, 210-217.

Bhattacharyya, S.C., 2012. Review of alternative methodologies for analysing offgrid electricity supply. Renewable and Sustainable Energy Reviews 16, 677-694.

Boussabaine, A.H., Elhag, T., 1999. Applying fuzzy techniques to cash flow analysis. Construction Management and Economics 17, 745-755.

Chanas, S., Zieliński, P., 2001. Critical Path Analysis in the Network with Fuzzy Activity Times. Fuzzy Sets and Systems 122, 195-204.

Chen, S.-P., 2007. Analysis of critical paths in a project network with fuzzy activity times. European Journal of Operational Research 183, 442-459.

Darling, S.B., You, F., Veselka, T., Velosa, A., 2011. Assumptions and the levelized cost of energy for photovoltaics. Energy \& Environmental Science 4, 3133-3139.

de Jager, D., Rathmann, M., 2008. Policy Instrument Design to Reduce Financing Costs in Renewable Energy Technology Projects, in: IEA-RETD (Ed.), ECOFYS. IEA-RETD, Netherlands.

DECC, 2011. UK Renewable Energy Roadmap, in: Change, D.o.E.a.C. (Ed.). Department of Energy and Climate Change, London.

Dubois, D., Prade, H., 1978. Operations on fuzzy numbers. International Journal of Systems Science 9, 613-626.

Dunlop, J., 2006. Wind Power Project Returns: What Should Equity Investors Expect? Journal of Structured Finance 12, 81-89.

Fight, A., 2005. Introduction to Project Finance. Elsevier Science \& Technology, Oxford.

Gökçek, M., Genç, M.S., 2009. Evaluation of electricity generation and energy cost of wind energy conversion systems (WECSs) in Central Turkey. Applied Energy 86, 2731-2739.

Gross, R., Heptonstall, P., Blyth, W., 2007. Investment in electricity generation: the role of costs, incentives and risks. UKERC, London.

Hamilton, K., 2006. Investment: Risk, Return and the Role of Policy. UKERC, London.

Heptonstall, P., 2007. A Review of Unit Cost Estimates. UK Energy Research Centre (UKERC).

IEA/NEA, 2010. Projected Costs of Generating Electricity. International Energy Agency / Nuclear Energy Agency / Organisation for Economic Co-operation and Development, Paris.

Kahraman, C., Beskese, A., Ruan, D., 2004. Measuring flexibility of computer integrated manufacturing systems using fuzzy cash flow analysis. Information Sciences 168, 77-94.

Kahraman, C., Ruan, D., Tolga, E., 2002. Capital budgeting techniques using discounted fuzzy versus probabilistic cash flows. Information Sciences 142, 57-76.

Lasher, W., 2010. Practical Financial Management, 6th ed. Cengage Learning, Inc., Mason. 
Locatelli, G., Mancini, M., 2010. Small-medium sized nuclear coal and gas power plant: A probabilistic analysis of their financial performances and influence of $\mathrm{CO} 2$ cost. Energy Policy 38, 6360-6374.

Locatelli, G., Mancini, M., 2011. Large and small baseload power plants: Drivers to define the optimal portfolios. Energy Policy 39, 7762-7775.

Messineo, A., Volpe, R., Marvuglia, A., 2012. Ligno-cellulosic biomass exploitation for power generation: A case study in sicily. Energy 45, 613-625.

Mott MacDonald, 2010. UK Electricity Generation: Costs Update. Mott MacDonald, Brighton.

UNEP, 2012. Global Trends in Renewable Energy Investment 2012. United Nations Environment Programme, Frankfurt.

van Dyken, S., Bakken, B.H., Skjelbred, H.I., 2010. Linear mixed-integer models for biomass supply chains with transport, storage and processing. Energy 35, 1338-1350. Wiser, R., Kahn, E., 1996. Alternative Windpower Ownership Structures. Lawrence Berkeley National Laboratory, Berkeley.

Wiser, R., Pickle, S., 1997. Financing Investments in Renewable Energy: The Role of Policy Design and Restructuring. Lawrence Berkeley National Laboratory, Berkeley.

Wiser, R.H., Pickle, S.J., 1998. Financing investments in renewable energy : the impacts of policy design. Renewable and Sustainable Energy Reviews 2, 361-386.

Zadeh, L.A., 1965. Fuzzy sets. Information and Control 8, 338-353.

Zadeh, L.A., 2002. Toward a Perception-Based Theory of Probabilistic Reasoning, in: Dimitrov, V., Korotkich, V. (Eds.), Fuzzy Logic: A Framework for the New Millennium. Springer-Verlag Berlin and Heidelberg GmbH \& Co. KG, Heidelberg. Zangeneh, A., Jadid, S., Rahimi-Kian, A., 2011. A fuzzy environmental-technicaleconomic model for distributed generation planning. Energy 36, 3437-3445.

Zimmerman, H.-J., 1990. Fuzzy Set Theory and Its Applications, 2nd edtion ed. Kluwer Academic Publishers, Dordrecht. 